University of Rhode Island

DigitalCommons@URI

2016

\title{
Missing the tide? Workplace cultural differences as a barrier to seafarer mobility in the U.S. workboat and sail training sectors
}

Eric Romelczyk

Austin Becker

University of Rhode Island, abecker@uri.edu

Follow this and additional works at: https://digitalcommons.uri.edu/maf_facpubs

The University of Rhode Island Faculty have made this article openly available.

Please let us know how Open Access to this research benefits you.

This is a pre-publication author manuscript of the final, published article.

Terms of Use

This article is made available under the terms and conditions applicable towards Open Access

Policy Articles, as set forth in our Terms of Use.

Citation/Publisher Attribution

Romelczyk, E.; Becker, A., Missing the tide? Workplace cultural differences as a barrier to seafarer mobility in the US workboat and sail training sectors. Maritime Policy \& Management 2016, 43 (7), 843-859.

Available at: http://dx.doi.org/10.1080/03088839.2016.1185182

This Article is brought to you for free and open access by the Marine Affairs at DigitalCommons@URI. It has been accepted for inclusion in Marine Affairs Faculty Publications by an authorized administrator of DigitalCommons@URI. For more information, please contact digitalcommons-group@uri.edu. 
Missing the tide? Workplace cultural differences as a barrier to seafarer mobility in the U.S. workboat and sail training sectors

\section{ERIC ROMELCZYK, MMA* and AUSTIN BECKER, PHD**}

University of Rhode Island, Dept. of Marine Affairs

*Corresponding Author

Eric Romelczyk

P.O. Box 82

Brightwood, OR 97011

eric.romelczyk@gmail.com

1-401-241-7270

orcid.org/0000-0001-8713-0729

**University of Rhode Island

Department of Marine Affairs

Suite 203

1 Greenhouse Rd.

Kingston, RI 02881

orcid.org/0000-0001-9224-7913

Cite as : Romelczyk, E.; Becker, A., Mis sing the tide? Workplace cultural diffe rences as a ba rie $r$ to seafarer mobility in the US workboat and sail training sectors. Maritime Policy \& Management 2016, 43 (7), 843-859. 



\begin{abstract}
While previous research details the psychological and social benefits of sail training programs for amateur "trainees," much less is known about the value and transferability of sail training work experience in terms of professional development for seafaring careers. This article reviews the current state of scientific knowledge on sail training and presents the findings of a qualitative study of maritime recruiter perceptions at 10 United States flag workboat companies. Results suggest that the maritime industry may benefit from an improved understanding of the role that sail training programs and the sail training community can play in training and inspiring the next generation of motivated and professional seafarers. Workboat recruiters see positive and negative aspects of sail training experience and perceive cultural divides within the maritime industry that may affect a seafarers' job mobility, whether or not such divides actually exist.
\end{abstract}

Key Words

Human Resources, Sail Training, Seafarers, Work Culture, Maritime Trades, Labor Mobility, Tall Ships

\title{
1. Introduction
}

The merchant seafarer could benefit from learning the seamanship, powers of observation and resourcefulness that one learns by necessity under sail, and the sailor would do well to use those skills and powers to develop protocols, drills, and procedures that would reduce the tendency to "wing it." Both cases would improve safety at sea for everyone. (Chase, Forthcoming)

The sail training community suggests that training youth and utilizing traditional skills helps to develop professional seafarers who are well qualified for work in other maritime sectors. This assumption lends legitimacy to the work done in sail training programs, but is based largely on anecdotal evidence. The global maritime industry may benefit from an improved understanding of the role that the sail training community plays in training aspiring seafarers for maritime careers. The sail training community can benefit from an empirically-based understanding of the role its vessels and personnel play in training and inspiring the next generation of motivated, professional seafarers. This study provides such evidence through an exploration of the attitudes of recruiters from 10 major U.S. workboat companies towards job candidates with backgrounds in the traditional sailing community.

Sail training has long been understood to provide foundational knowledge for professional seafarers in all sectors of the maritime transportation industry. The U.S. Coast Guard (USCG) even today requires all officers to serve time aboard the square-rigged sailing vessel Eagle as part of their training regime. However, the use of sail training as a means to develop skills amongst professional, non-military, seafarers remains underutilized. The above quote, from Capt. Andy Chase ${ }^{\mathrm{i}}$, a leading expert in maritime education and training as well as a veteran seafarer with long experience in both sail training and deep sea shipping, describes well the value of sail training for seafarers in the commercial maritime industry. This study explores the transferability of skills and experience between different maritime jobs through the lens of maritime recruiter attitudes toward experience and skills gained outside of their particular sector of the maritime industry. Specifically, we examine the applicability of sail training 
experience for careers in the commercial maritime industry. As a career path for professional seafarers, sail training offers less pay and fewer benefits than the commercial sector and many eventually transition to the more lucrative workboat sector. Here we explore the attitudes of workboat recruiters toward sail training seafarers and the broader implications of these findings toward the recruitment, retention, and training of seafarers in the maritime industry.

We use 'sail training' as a blanket term that encompasses a wide range of programs and activities utilizing large sailing vessels $(>20 \mathrm{~m})$ as educational platforms. In the United States, non-profit organizations operate sail training ships as platforms for experiential education for youth far more than for the training of professional seamen (Aguiar, 2015). Many sail training programs are specifically designed to develop leadership skills, safety-consciousness, team communication, and a strong work ethic in trainees and crew. For example, Sea Education Association (SEA) - a well-established sail training organization in the United States sail training community - describes its mission thus: 'SEA offers students an interdisciplinary curriculum, on shore and at sea aboard tall ships, that provides challenging voyages of scientific discovery, academic rigor, and personal growth (2015).' The demands of safely operating large sailing vessels foster a foundation of basic skills in trainees and crew, including safe handling of lines and precise ship handling and navigation. These skills are critical to success in any seafaring sector of the maritime industry (see Appendix 4, 'Statement By Capt. Jonathan Kabak').

Seafarers working in the sail training community hold the same credentials and frequently receive their basic training from the same institutions as their counterparts in other sectors of the industry, such as the workboat sector. We use the terms 'workboat' or 'workboat sector' to encompass inland towing vessels, offshore towing vessels, and offshore supply vessels. This definition excludes deep-sea merchantmen, naval or government vessels, and passenger vessels. The nature of workboat operations - whether barge towing, ship docking assistance or offshore supply - demands skills and experience unique to those operations, and distinct from the general skillset expected of seafarers in any maritime sector. In this respect, the demands of workboat operations are not unlike those of sail training operations.

In this study, we explore how recruiters in the U.S. workboat sector view sail training experience when considering prospective new employees. The study illustrates how perceptions of cultural differences can impact recruitment between related industries, affecting workers' career paths and overall job mobility. We begin in Section 2 with some background on sail training and job seeking behaviors across industry subsectors. Section 3 describes the data collection and analysis methods. In Section 4, we present 3 of our key findings of 10 recruiters' views on desirable job candidates in general. Next we present findings on their views of sail training experience specifically. We analyze our findings with reference to established literature on sail training, occupational psychology, and sociology of the maritime industry and describe the patterns that emerged during coding of the interview data. Implications for theory are discussed in Section 5, followed by our conclusions in Section 6.

\section{Literature Review}

This study is informed by existing literature on the benefits of sail training practices, vocational education and training, organizational behavior, and social science research concerning the general population of professional seafarers. 


\subsection{Previous research on sail training}

Sail training research tends to focus on leadership development or character building for the youth trainees. McCulloch et al.. (2010) describe the effects of participation in a sail training program in terms of the psychological development of the participants, finding that program participation benefits trainees by building self-confidence and developing social skills. Although the study makes brief mention of 'technical skills (674),' the authors do not explore this aspect of sail training programs in depth. Studies like Norris and Weinman's exploration of psychological change in trainees during a sail training voyage likewise focus on the effects of sail training experience in terms of psychological and social development (1996). Several other recent studies find measurable psychological and social skills benefits of sail training experience (Grocott and Hunter 2009; Hayhurst et al.., 2015; Henstock, Barker and Knijink 2013; Kafka et al.., 2012). Capurso and Borsci (2013) used a quasi-experimental design to measure the benefits of sail training experience on adolescent trainees' self-concept (15). Huey et al.. (2014) compare sail training programs with other methods of leadership development in use at the United States Naval Academy. They find that the sail training program employed by the Navy is more effective in developing effective leadership skills among trainees than traditional naval indoctrination techniques. Similar studies have not extended to the U.S. workboat sector.

Ethnographic case studies conducted on a particular Australian sail training program (Gordon, et al. 1993) describe the effects of several voyages on specific members of the trainee population. Broader ethnographic research by McCulloch $(2004$; 2007) describes aspects of different types and structures of sail training programs in the United Kingdom. McCulloch (2007) focuses particularly on hierarchies and leadership structures within sail training programs. These studies vary in methodology and specific research goals, but all generally focus their attention on the trainee crew in sail training programs, as opposed to the professionals.

Borodina (2013) describes the role of sail training on large sailing vessels for cadets in the Russian merchant marine but does not investigate the underlying assumptions regarding the effectiveness of sail training as professional development for these seafarers.

\subsection{Research on maritime education and training}

Professional benefits accruing to the professional sail training crew remain less understood. In fact, formal research focusing on maritime education and training (MET) practices and standards is a relatively recent development. Tarver and Pourzanjani (2003) discuss policy options for maintaining and developing the professional skills of seafarers in the United Kingdom. Researchers at the Seafarer's International Research Center (SIRC) in Cardiff have produced several studies on methods of assessing seafarer technical competence (Sampson, Gekara, and Bloor 2011; Ghosh, et al. 2014). These studies indicate that, despite domestic and international regulations and standards, the quality of training available across the global maritime industry is mixed and the maritime industry would benefit from developing effective methods for providing basic seamanship, navigation and shiphandling training to seafarers. However, these studies have been made in an international context and no comparable studies have yet been made specific to maritime education in the United States.

Several studies ( $\mathrm{Ng}$ et al. 2009; Pallis and $\mathrm{Ng} \mathrm{2011)} \mathrm{explore} \mathrm{motivations} \mathrm{and} \mathrm{expectations} \mathrm{among}$ seafarers enrolled in formal MET programs. These studies were conducted in an international context and do not directly discuss the role of sail training techniques in an MET program or curriculum. 


\subsection{Research on the psychology of hiring and job seeking}

Both the sail training sector and the workboat sector cultures in the U.S. are unique and idiosyncratic. Recruiters in these industries tend to describe themselves as very selective in their hiring decisions. To help understand such an environment, we refer to the substantial body of research that describes employer hiring practices and the psychology of job-seeking and hiring in white-collar contexts, which share some similarities regarding idiosyncratic culture and selective hiring (Coverdill and Finlay 1998; Sekiguchi 2004; Sekiguchi and Huber 2011; Rivera 2012). Rivera (2012), for example, presents the hiring process as 'cultural matching (1006)' between employer and employee based upon markers of perceived cultural similarity. This concept applies well to our study, as both the sail training and workboat sectors possess rich traditions borne from the rigors of the seafaring lifestyle and the demands of the work. We thus anticipate that recruiters will highly weight cultural matching. Perceptions that an employee's job performance will be affected by his or her ability to fit into the culture of the organization can influence hiring decisions, particularly when the workplace environment is as marked by long-established traditions and attitudes as the maritime industry.

Coverdill and Finlay (1998) explore the psychology of corporate recruiters and their perceptions of the hiring process. That study also emphasizes the importance many recruiters place on employee 'fit' - a somewhat nebulous concept grounded in emotional processes and interpersonal 'chemistry' (106) predicting the likelihood of future job performance.

Sekiguchi (2004) provides a review of the existing literature on the concepts of person-job fit and person-organization fit, emphasizing the perceived link between high levels of both types of fit and employee job performance. Sekiguchi and Huber (2011) offer findings from two quantitative studies of the effect of employer perceptions of person-job fit and person-organization fit on hiring decisions. That study concludes that the effect of the two types of perceived fit on hiring decisions is likely to vary depending on the requirements of specific jobs. The concept of person-job fit and its role in hiring decisions may be particularly relevant to the findings of this study, given the importance of technical skills training in maritime professions and the challenges candidates from outside the workboat sector face regarding certain technical skills ${ }^{\mathrm{ii}}$.

\subsection{Sociological and Psychological Research on Professional Seafarers and the Maritime Industry}

Although the field of occupational psychology is well developed, research specific to seafarers and the maritime industry forms a much smaller body of literature (McLaughlin, 2015). These jobs require long periods of time at sea, away from home and family. The demands of the jobs themselves generally include periods of hard physical labor, exposure to weather, extreme temperatures, and other workplace hazards, long hours with little rest, and the mental strain of maintaining constant situational awareness. This combination of elements makes seafaring jobs unique among peacetime professions. Barnett et al.. (2006) discuss maritime career paths and various factors that affect maritime career mobility and distinguish the maritime working environment from shore-based industries, finding that seafaring careers involve unique combinations of stressors and cultural elements not generally found in shoreside professions. Barnett et al. also find that many - though by no means all - seafarers tend to pursue shorebased work at some point in their careers, likely as a result of these factors. Inoue (2010) studies the career paths pursued by seafarers in the Japanese merchant maritime, concluding that many Japanese seafarers are likely to pursue shore-side work given the opportunity, but that a shortage of seagoing 
billets in the Japanese merchant maritime is likely to hinder younger seafarer's advancement into such shore-side positions. Although this research studies mobility between shore-based and seagoing positions, findings showing a high degree of transferable skills between seagoing and shore-based positions can be applied to the context of seafarers transitioning between seagoing jobs in different sectors of the industry, as in the present study.

Oldenburg and Jensen (2012), in studying occupational hazards in the modern maritime industry, conclude that 'the workplace on board a ship is unique and not comparable with the working conditions ashore (685).' They argue that this is due to the combination of strenuous physical demands, fatigue, psychological strain and the necessity of performing an inherently dangerous job for long periods of time away from home and family. Mitroussi and Notteboom (2014) concur, further noting that these factors demand caution in applying insights from non-maritime occupational research (15). Ljung and Lutzhof (2014) discuss perceptions of work and performance in certain sectors of the maritime industry, echoing the studies previously mentioned and noting the distinctions between working environments in different sectors of the industry. The recognition that job demands and stressors can vary markedly between similar jobs in different maritime sectors is significant in exploring factors that affect career mobility between sectors.

Leggate (2004) discusses the implications and likelihood of a global labor shortage in the maritime industry, concluding that some degree of labor shortage may indeed arise in the near future. Leggate further notes the importance of sufficient training for current and aspiring seafarers, arguing that quality of labor, as well as quantity, should be of concern to the maritime industry.

'The Global Seafarer,' a publication produced by the International Labor Organization (ILO), provides useful background on the global maritime labor market as well as an overview of the global maritime industry (ILO 2004). Little work, however, has explored workplace culture in the U.S. sail training community and workboat sector, or the factors which might distinguish these particular work environments from the maritime industry overall. In the following section, we describe our methodology and explain how existing bodies of research on maritime work and culture influenced our data collection and analysis.

\section{Methods}

\subsection{Sampling Strategy}

This exploratory study focuses on the 149 companies listed in the annual U.S. Army Corps of Engineers database "Waterborne Transportation Lines of the U.S." that operate tugboats, river pushboats, and/or oilfield supply vessels registered under the U.S. flag, with a fleet size of 10 or more vessels. These companies are represented in the persons of the recruiters and/or personnel managers that we interviewed. We focused our efforts on the workboat sector of the U.S. maritime industry in this study as the lead author's personal experience as a professional mariner within this context provided familiarity with the study population, allowing us to quickly identify an appropriate sample. Personal familiarity also enabled better communication with study participants and deeper understanding of participant responses.

"Waterborne Transportation Lines of the U.S." indicates 1,428 U.S. companies that own or operate such vessels under the U.S. flag (Waterborne Commerce Statistics Center, 2013). We excluded 
companies with fleet sizes smaller than 10 vessels from this study, as smaller companies are less likely to have dedicated recruiters, personnel managers or human resources departments. This left 149 companies fitting our criteria. To mitigate inconsistencies in vessel type, crew size, and operating environment across geographical areas, we categorized the sample by company operating region and operational parameters - for example, offshore towing as opposed to river towing operations, ensuring the quality of data through triangulation of sources ${ }^{\mathrm{iii}}$ We sorted this population by one of four primary operating regions within U.S. waters - the U.S. East Coast, West Coast, Gulf Coast and inland/Great Lakes waterways (Table 1, 'Populations and Sample'), aiming for maximum geographical variation in our sample (Savin-Baden and Major 2013).

\section{TABLE 1 HERE}

We then sought contact information for recruiters or personnel managers at these companies through recommendations from colleagues, LinkedIn, and other networking efforts. In some cases we were unable to find contact information for specific individuals and were forced to "cold call" companies through their Human Resources Departments to request interviews. In all, we contacted individuals from 25 companies on our list of the 149 largest U.S. flag workboat operators. 15 of those contacted either did not respond or refused to participate, leaving us with 10 companies that represent about $7 \%$ of the total population of companies operating more than 10 vessels. Of the companies we contacted to request interviews, only those for which we had acquired contact information for specific individuals within the company agreed to participate. "Cold calls" did not yield any interviews. In refusing to participate in the study, two individuals expressed concern about discussing hiring practices at their companies and one individual stated that she was "too busy" to participate. One individual stated that his company could provide no useful information and an interview would be a "waste of [our] time."

As this is a qualitative and exploratory study informed by grounded-theory principles, we chose our sample size based on data saturation (Robinson 2014). An assessment of the body of interview data suggests the tenth interview as the point of data saturation, beyond which further data collection would be unlikely to add significant new insights to our findings. As we state below (see section 5.4), the design of the present study is exploratory in nature. We do consider that the findings of the present study could be expanded upon in future research involving larger samples.

\subsection{Sample Characteristics}

The principle of data saturation - as well as limitations on time and human resources - ultimately determined the sample size of 10 and the data collection schedule of one interview per organization and study participant. Thus, the sample for this study consisted of 10 personnel responsible for hiring at 10 different workboat companies, identified herein as P1-P10 (Table 2, 'Sample Characteristics'). In this table we characterize participants by attributes such as primary operating region and type of operations of their company as well as by the individual's demographic characteristics. Individual job titles and job responsibilities varied between participants. For some, the primary or sole responsibility of their position was recruiting. For others, recruiting formed a less significant part of their job responsibilities.

\section{TABLE 2 HERE}

\subsection{Data Collection}

This study used a semi-structured interview format. We asked ten open-ended questions (see Appendix 
1, 'Interview Questionnaire') about work histories, candidate vetting and hiring preferences, and specific views on the applicability of sail training experience to employment at their company. In some cases, we asked additional follow-up questions where responses seemed unclear. We conducted interviews by telephone, due to geographical constraints. In cases where participants agreed to allow the interviews to be recorded, these interviews were later transcribed for analysis. Three of the ten participants declined to allow recording of their interviews. In those cases, we based data analysis on detailed notes taken during the interview.

\subsection{Data Analysis}

To analyze the interview data, we began by open coding to identify common categories in participant responses such as 'professionalism' or 'lack of commitment to employer.' In a second round of coding, we compared sets of coded interview data to highlight key patterns and repeating themes. We used a grounded-theory coding approach (Strauss and Corbin 1998; Roulston 2014; Reichertz 2014; Thornberg and Charmaz 2014) to explain the attitudes of our sample of recruiters in the U.S. workboat sector toward candidates with sail training experience. The themes, which emerged during open coding, are detailed in Appendix 2 'Coding Scheme.' To confirm the suitability of the coding scheme, we subjected the coding scheme and analysis of interview data to peer examination with colleagues in our research group ${ }^{\mathrm{iv}}$.

\section{Summary of Findings}

In this section, we report three of the major findings of this study, organized around the following broad categories: attributes which participants found desirable in job applicants, participant views of sail training experience, and overall participant familiarity with the sail training community.

\subsection{Prior Workboat Experience Plays a Significant Role in Hiring Decisions}

All 10 participants indicate that workboat experience represents a significant factor in the hiring decisions they make. All participants express the belief that certain skills necessary in workboat operations cannot be learned except by experience or training specific to workboats. Four participants report that lack of workboat experience would present a significant obstacle for job seekers at their companies. Two participants state that this obstacle could be overcome if candidates entered at lower positions (e.g. rating as opposed to officer) and/or were willing to undergo additional training. The remaining participants report that they assess all candidates on a case-by-case basis, declining to make further general statements on individual candidates' skills and/or experience.

P6 and P10 regard a lack of workboat experience as a disqualification for a candidate, regardless of other factors. P10 further elaborates on his reasoning, 'There are enough people that are available on what we call "offshore boats" [n.b.: coastal and ocean tugs, in this case] that are better qualified...and can do the job on day 1. (P10)'

\subsection{A Majority of Participants Value Intangible Attributes In Candidates}

A majority of participants also report certain intangible attributes that they value in candidates (Table 2, 'Intangible Attributes Referenced As Desirable'). These are psychological, emotional, or cognitive attributes cannot be reduced to credentials or job history. Participants who discuss intangible attributes in job candidates also report using job history as evidence of a candidate's likely intangible attributes: 'we're looking for...leadership qualities...responsible, safety-conscious, environmentally sound seafarers 
that have had prior success in their field, having had no incidents of any kind (P8, emphasis added).'

\section{TABLE 3 HERE}

\subsection{Participant Views of Candidates With Sail Training Varied}

We find no uniform perception of sail training experience among study participants (Table 3, 'Participant Views of Candidates With Sail Training Experience'). Eight participants express willingness to hire a candidate with sail training experience. Five participants perceive unique added value in a candidate's sail training experience, usually expressing this in terms of intangible attributes that they expected to find in such candidates. Two perceive sail training negatively, and would not be willing to hire a candidate with such experience. Three participants who do not perceive unique value in a candidate's sail training experience would nonetheless be willing to hire such candidates if they otherwise met job requirements.

\section{TABLE 4 HERE}

To summarize, we find that participants express concern about a lack of cultural fit in hiring candidates from outside the workboat sector. Further, they place great importance on candidates' credentials and work experience. Candidates' intangible attributes also play a role in hiring decisions. Participant views on sail training experience are mixed, ranging from markedly positive to distinctly negative, but most express neutral to mildly positive views on sail training experience. In the next section, we relate the major findings of this study to existing literature and examine implications for the professional relevance of sail training experience and job mobility in the U.S. maritime industry.

\section{Discussion}

Results of interviews suggest that recruiters in the U.S. workboat sector prefer to hire candidates with credentials and experience specific to the workboat sector. In fact, some base hiring decisions solely upon the basis of such job history and credentials. However, others also look for attributes that cannot be reduced to job history and credentials. For example, P8 looks for evidence of a candidate's leadership abilities and awareness of safety practices, while P4 prefers to hire candidates who show ambition and commitment to a seagoing career. We call these 'intangible' attributes (see Table 2, above). We discuss the implications of this finding in greater detail below.

\subsection{Operating Environment and Culture, Workboat Sector}

Many recruiters view the culture of the U.S. workboat sector as unique and prefer to hire candidates who already share this professional background. Participants use terms such as 'industrial (P6)' or 'tugboat (P9)' to describe the cultural environment of the workboat sector, often suggesting that candidates without this background may not possess certain attributes necessary to succeed in such an environment.

Concerning hiring in the context of white-collar professionals, Rivera (2012) notes: 'Concerns about shared culture were highly salient to employers and often outweighed concerns about productivity alone (999, emphasis added).' The maritime industry possesses a strong professional culture (Oldenburg and Jensen 2012, Ljung and Lutzhof 2014, Mitroussi and Notteboom 2014, ILO 2004) built on longstanding traditions, in which seafarers' experience is not merely an indication of technical skills but also of immersion in seafaring life and traditions. Given this context, we suggest that in the 
maritime industry, a seafarer's professional background serves as the kind of cultural marker that Rivera refers to above.

Some participants view candidates with sail training experience as particularly lacking in work ethic (P1, P3, P9) or professional discipline (P10, P3, P6). Such judgments of 'fit' (Coverdill and Finlay 1998) are based upon cultural values that participants believe do not exist, or are not present to the necessary degree, in the sail training community. All participants were questioned regarding their actual knowledge of sail training (see Appendix 3) and none reported any firsthand sail training experience. We consider, therefore, that participants are unlikely to be familiar with the standards, practices, and cultural values actually existing within the sail training community.

In regard to the culture of maritime working conditions more generally, Mitroussi and Notteboom note that, 'the job is of a highly technical nature and has been characterized by risk...and toughness... (2014, 8).' The operation of a sail training vessel entails many of the same demands as the operation of any commercial vessel in terms of necessary skills and tolerance for working conditions. Those recruiters unfamiliar with sail training may not recognize these basic similarities, and may overstate the degree to which sail training differs from commercial maritime operations.

In contrast to the participants above, five participants (P2, P4, P5, P7 and P8) state - some quite strongly - that sail training experience can in some ways predict good fit for a workboat job. Their views are rooted in positive perceptions of sail training culture and a belief that skills learned from sail training experience can be readily adapted to the demands of the workboat sector. Despite their lack of direct experience with sail training, these participants view sail training work as potentially conducive to a candidate's adaptation to a new environment on a workboat.

\subsection{Credentials and Experience}

In the U.S. workboat sector, officers must possess additional USCG credentials above and beyond the normal license required of all management-level seafarers. To earn these credentials, U.S. seafarers must document experience on workboats and demonstrate competence in shiphandling and seamanship skills specific to workboat operations, such as barge towing or operating dynamic-positioning systems.

Nearly all participants mention that potential candidate's possession of these additional, workboatspecific credentials are a key factor in their hiring decisions. P5 and P8 are notable exceptions. At P8's company, a candidate without these credentials should expect to enter as a 'rating' and undergo a company training program. P5 mentions similar in-house training programs at his company. Several participants imply in their responses that a candidate with officer's credentials would be viewed with favor even if officer's credentials were not a requirement of the position.

Participants who base hiring decisions mainly on a candidate's paper credentials and experience prefer not to hire candidates from outside of the workboat sector. Sekiguchi and Huber (2011) argue that items such as a candidate's credentials and work experience act as predictors of 'person-job (PJ)' fit. They further conclude that recruiters weight these predictors heavily for certain jobs because 'a high level of PJ fit has a stronger impact on post-hire outcomes when advanced knowledge and expertise are critical for performing the job (206).' Research shows that seafaring jobs are highly demanding of seafarers' technical skills, professional judgment and psychological resilience (Mitroussi and Notteboom 2014, Ljung and Lutzhof 2014, Oldenburg and Jensen 2012). Items predicting PJ fit 
generally fall into the category of tangible attributes like knowledge and skills (Sekiguchi 2004, 187188), which can be determined by straightforward inspection of a candidate's resume and credentials.

We argue that participants who focus on candidates' work experience and credentials weight these so heavily because they believe that the demands of seafaring jobs dictate high levels of PJ fit in candidates. This places seafarers from the sail training community - without additional workboat credentials or prior workboat experience - at a disadvantage in these recruiters' eyes. However, research on PJ fit also suggests that, being heavily influenced by an individual's knowledge and technical skills, PJ fit can increase with time and training (Sekiguchi 2004, Sekiguchi and Huber 2011). This suggests that participants' concerns with poor PJ fit between candidates with sail training experience and jobs in the U.S. workboat sector may be overstated, provided employers are willing to train and orient new hires.

\subsection{Intangible Qualities in Hiring}

Research on maritime education and employment (Tarver and Pourzanjani 2003, Leggate 2004, Sampson et al. 2011, Ghosh et al. 2014) suggests that employers are increasingly concerned with the quality of maritime labor. A study by the SIRC notes '...the need to test for less tangible personal qualities such as "confidence" (Sampson et al. 2011, 89),' Another study conducted at the Australian Maritime College emphasizes the importance of training seafarers in '...a higher level of cognitive skill required...for decision making and problem solving (Ghosh et al. 2014, 55).' Recruiters cannot determine these attributes by inspecting a candidate's resume or credentials. Participants in the current study who report valuing certain intangible attributes (see Table 2) report making inferences about these intangible attributes from items such as candidates' 'demeanor (P8),' appearance, or work history.

In the current study, participants who did value 'less tangible' attributes tended to value items such as a strong work and community ethic, evidence of leadership skills or leadership potential, motivation and ambition. Research on sail training finds positive benefits for trainees in those areas (Norris and Weinman 1996, McCulloch 2004, McCulloch 2007, McCulloch 2010, Capurso and Borsci 2013, Huey et al. 2014). Although existing research focuses on the trainee crew members of sail training vessels, we expect that similar benefits are likely to accrue to the professional crew members aboard such vessels as well. Thus, a recruiter familiar with the sail training community could infer such desirable

attributes from a candidate's sail training experience. Recruiters unfamiliar with the sail training community, however, may not make this connection.

\section{$5.4 \quad$ Limitations}

There are a number of limitations that must be considered with respect to this exploratory study. Small sample size and non-random sampling technique may limit generalizability to other contexts. Logistical constraints, particularly time constraints, influenced these factors. This limitation is mitigated by the distribution of the sample across a number of distinct sub-categories within the U.S. workboat sector, and by the selection of participants based on the size of the employer's maritime workforce.

\section{Conclusions}

Our findings suggest that maritime recruiters value the very same intangible attributes in candidates that the sail training community develops through the missions of its programs. Many sail training programs focus on building attributes such as leadership, resourcefulness, work ethic, or community ethics (SEA, 2015). Proponents within the sail training community believe that the value of these 
programs lies in their effectiveness in character building and leadership (see Appendix 4). Many recruiters in the U.S. workboat sector find these attributes desirable in job applicants. Not all recruiters, however, connect sail training experience with these attributes.

Perceived cultural differences, or lack of good fit, between the workboat sector and the sail training community make some recruiters wary of hiring seafarers with sail training backgrounds. This perception constitutes a personal bias that our findings suggest impacts hiring decisions. Recruiters perceive sail training experience to be fundamentally different from - or even inferior to - commercial maritime experience, a perception that may be exaggerated by lack of familiarity with sail training operations and practices. This lack of familiarity creates a blind spot in the recruitment of qualified seafarers - this in a time when research suggests the maritime industry may be facing shortages in both quantity and quality of seagoing labor. If this divide exists between the workboat sector and the sail training community in the U.S. maritime industry, it likely exists between other maritime sectors. This would present an obstacle to seafarers' job mobility that - as our study suggests - appears to be based as much in perception as in reality.

On the other hand, some recruiters seem to perceive sail training experience as a positive attribute for a candidate, believing that sail training experience implies desirable intangible attributes such as leadership abilities, resourcefulness, work ethic, professionalism, and community ethics. Indeed, research suggests that sail training programs aim to develop these qualities in trainees and such attributes likely extend to the professional seafarers employed on these vessels as well.

Given documented concerns regarding the quality of education and training in the maritime industry, maritime employers should pursue all potential sources of qualified personnel, including those transitioning from sail training. Since sail training programs are also designed around the education of young people, closer cooperation between the sail training community and commercial maritime interests could inspire youth to embark upon maritime careers and form the next generation of motivated, professional seafarers. Lack of cooperation or familiarity between the sail training community and the overall maritime industry thus represents a missed opportunity for both parties.

\section{Acknowledgements}

The authors would like to extend particular thanks to the following for their assistance and support: Capt. Andy Chase, Marine Transportation Department, Maine Maritime Academy; Capt. Timothy Leach, Director of Career Services, Maine Maritime Academy; Capt. Jonathan Kabak, Director of Sail Training, U.S. Merchant Marine Academy; Bert Rogers and Lori Aguiar, Tall Ships America, Capt. John Worth, Capt. Chris Gasiorek, Ms. Elizabeth Greco, and the individuals and organizations participating in the present study.

\section{Disclosure Statement}


The authors reported no potential conflict of interest

i Professor of Marine Transportation at Maine Maritime Academy, author of Auxiliary Sail Vessel Operations for the Aspiring Professional Mariner, $2^{\text {nd }} e d$. (Forthcoming).

ii Study participants refer to skills such as barge towing operations or working with dynamic-positioning systems, which are only applicable to tugs or offshore supply vessels respectively and not to other types of commercial vessels.

iii 'Triangulation may be of data (time, space and persons)...Triangulation means that the researcher has multiple data points that can broaden their understanding of the subject of their research (Savin-Baden and Major 2013, p.477).'

iv 'In an external audit, an expert not involved in the process examines the processes and products (Savin-Baden and Major 2013, p. 479).' Two colleagues reviewed our coding scheme and data analysis and found no inconsistencies or gaps in either processes or end product. 
Missing the tide? Workplace cultural differences as a barrier to seafarer mobility in the U.S. workboat and sail training sectors

\section{References}

Aguiar, L. (ed.), 2015. Sail Tall Ships! A Directory of Adventure and Education Under Sail. 21st edition, Tall Ships America, Newport, RI.

Alderton, Tony, Michael Bloor, Erol Kahveci, Tony Lane, Helen Sampson, Michelle Thomas, Nik Winchester, Bin Wu, and Minghua Zhao. 2004. The Global Seafarer: Living and Working Conditions In a Globalized Industry. Geneva: International Labour Office.

Barnett, Michael, David Gatfield, Bent Overgaard, Claire Pekcan, and Allan Graveson. 2006. "Barriers to Progress or Windows of Opportunity? A Study in Career Path Mapping in the Maritime Industries." WMU Journal of Maritime Affairs 5 (2): 127-42.

Bills, David B. 1988. "Credentials and Capacities: Employers' Perceptions of the Acquisition of Skills." The Sociological Quarterly 29 (3): 439-49.

- 1990. "Employers' Use of Job History Data for Making Hiring Decisions: A Fuller Specification of Job Assignment and Status Attainment." The Sociological Quarterly 31 (1): 23-35.

2003. "Credentials, Signals, and Screens: Explaining the Relationship between Schooling and Job Assignment." Review of Educational Research 73 (4): 441-69.

Borodina, N. V. 2013. "USE OF SAIL TRAINING SHIP IN SEAFARERS' PROFESSIONAL EDUCATION." Asia-Pacific Journal of Marine Science \& Education 3: 87-96.

Capurso, Michele and Simone Borsci. 2013. "Effects of a sail training Sail Training Experience on Adolescents' Self-Concept." International Journal of Educational Research, no. 58: 15-24. doi:08830355 .

Coverdill, James E. and William Finlay. 1998. "Fit and Skill in Employee Selection: Insights from a Study of Headhunters." Qualitative Sociology 21 (2): 105-27.

Chase, G. Andy. Forthcoming. Auxiliary Sail Vessel Operations For The Aspiring Professional Mariner. 2nd ed. Maryland: Cornell Maritime Press.

Doyle, N., Malcolm McLachlan, Alistair Fraser, Ralf Stilz, Karlien Lismont, Henriette Cox, Joanne McVeigh. 2015. "Resilience and well-being amongst seafarers: cross-sectional study of crew across 51 ships." International Archives of Occupational and Environmental Health, 1-11, doi:10.1007/s00420015-1063-9.

Garnett, Bruce, Neil Guppy, and Gerry Veenstra. 2008. "Careers Open to Talent: Educational Credentials, Cultural Talent, and Skilled Employment." Sociological Forum 23 (1): 144-64. doi:10.1111/j.1573-7861.2007.00049.x.

Ghosh, Samrat, Marcus Bowles, Dev Ranmuthugala, and Ben Brooks. 2014. "Reviewing Seafarer 
Missing the tide? Workplace cultural differences as a barrier to seafarer mobility in the U.S. workboat and sail training sectors

Assessment Methods to Determine the Need for Authentic Assessment." Australian Journal of Maritime \& Ocean Affairs 6 (1): 49-63. doi:10.1080/18366503.2014.888133.

Gordon, Sandy, Kate Harcourt-Smith, Kirsten Hay, and Simon Priest. 1993. "Case Study of 'Blue Watch' on STS Leeuwin.” Journal of Adventure Education and Outdoor Leadership 13 (1): 4-7.

Grocott, Andrew and John Hunter. 2009. "Increases in Global and Domain Specific Self-Esteem Following a 10 Day Developmental Voyage." Social Psychology of Education, no. 12 (January): 44359. doi:DOI 10.1007/s11218-008-9088-5.

Hayhurst, Jill, John Hunter, Sarah Kafka, and Mike Boyes. 2015. "Enhancing Resilience in Youth through a 10-Day Developmental Voyage." Journal of Adventure Education and Outdoor Learning 15 (1): 40-52. doi:10.1080/14729679.2013.843143.

Henstock, Murray, Katrina Barker, and Jorge Knijnik. 2013. '2, 6, Heave! Sail Training’s Influence on the Development of Self-Concept and Social Networks and Their Impact on Engagement with Learning and Education. A Pilot Study." Australian Journal of Outdoor Education 17 (1): 32-46.

Huey, Wesley S., David G. Smith, Joseph J. Thomas, and Charles R. Carlson. 2014. "The Great Outdoors: Comparing Leader Development Programs at the U.S. Naval Academy." Journal of Experiential Education 37 (4): 367-81. doi:10.1177/1053825914547625.

n.d.

Inoue, Kinzo. 2011. "Maritime Community and Its Human Resource Mobility." The Journal of Navigation, no. 64: 633-43. doi:10.1017/S037346331100018X.

Kafka, Sarah, John A. Hunter, Jill Hayhurst, Mike Boyes, R. L. Thompson, H. Clarke, Andrew M. Grocott, M. Stringer, and K.S. O’Brien. 2012. “A 10-Day Developmental Voyage: Converging Evidence from Three Studies Showing That Self-Esteem May Be Elevated and Maintained without Negative Outcomes." Social Psychology of Education, no. 15: 571-601. doi:10.1007/s11218-0129177-3.

Lau, Y.Y. and Ng, A.K.Y. Forthcoming. "The motivations and expectations of students pursuing maritime education." WMU Journal of Maritime Affairs (in press, doi: 10.1007/s13437-015-0075-3).

Leggate, Heather. 2004. "The Future Shortage of Seafarers: Will It Become a Reality?" Maritime Policy and Management 31 (1): 3-13. doi:10.1080/03088830310001642049.

Ljung, Margareta and Margareta Lutzhoft. 2014. "Functions, Performances and Perceptions of Work on Ships.” WMU Journal of Maritime Affairs, no. 13: 231-50. doi:10.1007/s13437-014-0057-x.

McCulloch, Ken. 2004. "Ideologies of Adventure: Authority and Decision Making in Sail Training." Journal of Adventure Education and Outdoor Learning 4 (2): 185-98.

doi:10.1080/14729670485200531. 
Missing the tide? Workplace cultural differences as a barrier to seafarer mobility in the U.S. workboat and sail training sectors

- 2007. "Living at Sea: Learning from Communal Life Aboard Sail Training Vessels." Ethnography and Education 2 (3): 289-303. doi:10.1080/17457820701547286.

McCulloch, Ken, Pat McLaughlin, Pete Allison, Vivien Edwards, and Lyn Tett. 2010. "Sail Training as Education: More than Mere Adventure." Oxford Review of Education 36 (6): 661-76. doi:10.1080/03054985.2010.495466.

McLaughlin, H. 2015."Seafarers in the spotlight." Maritime Policy \& Management, 42(2): 95-96.

Mitroussi, Kyriaki and Theo Notteboom. 2014. "Getting the Work Done: Motivation Needs and Processes for Seafarers and Dock Workers." WMU Journal of Maritime Affairs. doi:10.1007/s13437014-0064-y.

Ng, A.K.Y., Koo, A.C. and Ho, W.C.J. 2009. "The motivations and added values of embarking on postgraduate professional education: evidences from the maritime industry." Transport Policy 16(5): 251-258.

Norris, Richard and John Weinman. 1996. "PSYCHOLOGICAL CHANGE FOLLOWING A LONG SAIL TRAINING VOYAGE." Personality and Individual Differences 21 (2): 189-94. doi:SO1918869(96)00069.

Oldenburg, Marcus and Hans-Joachim Jensen. 2012. "Merchant Seafaring: A Changing and Hazardous Occupation." Occupational and Environmental Medicine 69 (9): 685-88. doi:10.1136/oemed-2011100619.

Pallis, A.A. and Ng, A.K.Y. 2011. "Pursuing maritime education: an empirical study of students' profiles, motivations and expectations." Maritime Policy \& Management 38(4): 369-393.

Reichertz, Jo. 2014. "Induction, Deduction, Abduction." In The SAGE Handbook of Qualitative Data Analysis, edited by Uwe Flick. London: Sage Publications, Ltd.

Rivera, Lauren A. 2012. "Hiring as Cultural Matching: The Case of Elite Professional Service Firms." American Sociological Review 77 (6): 999-1022. doi:10.1177/0003122412463213.

Robinson, Oliver C. 2014. "Sampling in Interview-Based Qualitative Research: A Theoretical and Practical Guide." Qualitative Research in Psychology 11: 25-41. doi: 10.1080/14780887.2013.801543.

Roulston, Kathryn. 2014. "Analyzing Interviews." In The SAGE Handbook of Qualitative Data Analysis, edited by Uwe Flick, 297-312. London: Sage Publications, Ltd.

Sampson, Helen, Victor Gekara, and Michael Bloor. 2011. "Water-Tight or Sinking? A Consideration of the Standards of the Contemporary Assessment Practices Underpinning Seafarer License Examinations and Their Implications for Employers." Maritime Policy and Management 38 (1): 81-92. doi:10.1080/03088839.2010.533713. 
Missing the tide? Workplace cultural differences as a barrier to seafarer mobility in the U.S. workboat and sail training sectors

Savin-Baden, Maggi and Claire Howell Major. 2013. Qualitative Research: The Essential Guide To Theory And Practice. London: Routledge.

Sea Education Association. 2015. "Mission Statement." About SEA. http://www.sea.edu/about_sea/mission_statement. Accessed 03/20/2015.

Sekiguchi, Tomoki. 2004. "Person-Organization Fit and Person-Job Fit In Employee Selection - A Review of the Literature." Osaka Keidai Ronshu 54 (6): 179-96.

Sekiguchi, Tomoki and Vandra L. Huber. 2011. "The Use of Person-organization Fit and Person-job Fit Information in Making Selection Decisions." Organizational Behavior and Human Decision Processes, no. 116: 203-16. doi:10.1016/j.obhdp.2011.04.001.

Strauss, Anselm and Juliet Corbin. 1998. Basics of Qualitative Research: Techniques and Procedures for Developing Grounded Theory. 2nd ed. Thousand Oaks, CA: Sage Publications, Inc.

Tarver, Sean and Malek Pourzanjani. 2003. "Measuring and Sustaining the UK Maritime Skills Base: A Review." WMU Journal of Maritime Affairs 2 (1): 5-15.

Thornberg, Robert and Kathy Charmaz. 2014. "Grounded Theory and Theoretical Coding." In The SAGE Handbook of Qualitative Data Analysis, edited by Uwe Flick, 153-69. London: Sage Publications, Ltd.

Waterborne Commerce Statistics Center. 2013. Waterborne Transportation Lines of the United States. Vol. 2, Vessel Company Summary. 3 vols. Waterborne Transportation Lines of the U.S. New Orleans, LA: U.S. Army Corps of Engineers. http://www.navigationdatacenter.us/db/wtlus/xls/TS13OP.xlsx.

Willig, Carla. 2014. "Interpretation and Analysis." In The SAGE Handbook of Qualitative Data Analysis, edited by Uwe Flick, 136-48. London: Sage Publications, Ltd. 